\title{
Heteroaromatic Boron Compounds. XIII. On the Bromination and Nitration of Some Thieno-fused 3,2-Borazaropyridines
}

\author{
SALO GRONOWITZ* and CURT ROOS**
}

Division of Organic Chemistry 1, Chemical Center, University of Lund, P. O. Box 740, S-220 07 Lund 7, Sweden

\begin{abstract}
Derivatives of 4,5-borazarothieno[2,3-c]pyridine and 7,6-borazarothieno[3,2-c]pyridine were pre. pared from 2-acetyl-3-thiopheneboronic acid and 3-acetyl-2-thiopheneboronic acid by reaction with hydrazines. The bromination of these systems with different reagents was investigated. Preparatively useful yields of 2,3-dibromo derivatives were obtained with bromine and silver sulfate in concentrated sulfuric acid and with $N, N$-dibromoisocyanuric acid in concentrated sulfuric acid. Isomer distributions in the nitration of the two ortho acetyl. thiopheneboronic acids with fuming nitric acid in concentrated sulfuric acid were determined and compared with those obtained in the same nitration of the borazarothienopyridine systems. It was found that 2 -acetyl-4nitro-3-thiopheneboronic acid and 3-acetyl-5nitro-2-thiopheneboronic acid are rapidly deboronated at room temperature in alkaline medium.
\end{abstract}

In previous papers, it has been demonstrated that ortho-formylthiopheneboronic acids react with hydrazines under hydrazone formation and cyclodehydration to give borazarothienopyridines.1,2 It was found that these ring systems were stable towards hydrolysis ${ }^{1,2}$ and that they under weakly acidic or non-acidic conditions could be brominated or nitrated on the remaining $\mathbf{C}-\mathbf{H}$ position of the borazaropyridine ring. ${ }^{2-s}$ It was also found that under strongly acidic conditions nitration occurs in the thiophene ring."

Furan-fused 3,2-borazaropyridines have been prepared from ortho-formylfuranboronic

\footnotetext{
* To whom correspondence should be addressed. * Taken in part from the Ph.D. thesis of C. Roos, University of Lund 1974.
}

acids. ${ }^{-8}$ However, these compounds were less stable towards hydrolysis than the thiophene analogues, and attempts to carry out electrophilic substitution were unsuccessful. Recently also selenophene-fused 3,2-borazaropyridines have been synthesized from ortho-formylselenopheneboronic acids, but no investigations of their hydrolytic stability and of their aromatic substitution have been carried out."

In the present paper, the synthesis, bromination and nitration of primarily $C$-methyl substituted thieno-fused 3,2-borazaropyridines will be discussed.
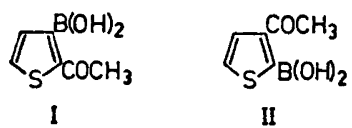

Starting from 2-acetyl-3-thiopheneboronic acid (I) and 3-acetyl-2-thiopheneboronic acid (II), for which several methods of synthesis have been described earlier, ${ }^{10}$ 7-methyl-4,5borazarothieno[2,3-c]-pyridines (III) and 4methyl-7,6-borazarothieno[3,2-c]pyridines (IV) were prepared in high yield by reaction with hydrazine (IIIa and IVa) and methylhydrazine (IIIb and IVb). From IIIa, the $\mathrm{B}-\mathrm{CH}_{3}$ derivative (IIIc) was prepared by refluxing with butanol accompanied by water separation, and addition of methylmagnesium iodide after removal of the excess butanol. In the same way, the 4,7-dimethyl-(IVc) and 4,6,7-trimethylderivatives (IVd) were prepared from IVa and $\mathrm{IVb}$, respectively.

The structures followed from elemental analyses, NMR and mass spectra. The mass spectra

Acta Chem. Scand. B 29 (1975) No. 10 


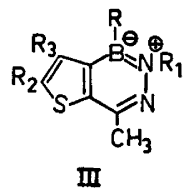

a $\mathrm{R}=\mathrm{OH}, \mathrm{R}_{1}=\mathrm{R}_{2}=\mathrm{R}_{3}=\mathrm{H}$

b $\mathrm{R}=\mathrm{OH}, \mathrm{R}_{1}=\mathrm{CH}_{3}, \mathrm{R}_{2}=\mathrm{R}_{3}=\mathrm{H}$

c $\mathrm{R}=\mathrm{CH}_{3}, \mathrm{R}_{1}=\mathrm{R}_{2}=\mathrm{R}_{3}=\mathrm{H}$

d $\mathrm{R}=\mathrm{OH}, \mathrm{R}_{1}=\mathrm{H}, \mathrm{R}_{2}=\mathrm{R}_{3}=\mathrm{Br}$

o $\mathrm{R}=\mathrm{OH}, \mathrm{R}_{1}=\mathrm{CH}_{3}, \mathrm{R}_{2}=\mathrm{R}_{3}=\mathrm{Br}$

f $R=O H, R_{1}=R_{3}=H, R_{2}=\mathrm{NO}_{2}$

g $\mathrm{R}=\mathrm{OH}, \mathrm{R}_{1}=\mathrm{R}_{2}=\mathrm{H}, \mathrm{R}_{3}=\mathrm{NO}_{2}$

h $\mathrm{R}=\mathrm{OH}, \mathrm{R}_{1}=\mathrm{CH}_{3}, \mathrm{R}_{2}=\mathrm{NO}_{2}, \mathrm{R}_{3}=\mathrm{H}$

i $\mathrm{R}=\mathrm{OH}, \mathrm{R}_{1}=\mathrm{CH}_{3}, \mathrm{R}_{2}=\mathrm{H}, \mathrm{R}_{3}=\mathrm{NO}_{2}$

of the $\mathrm{B}-\mathrm{OH}$ derivatives showed, besides the molecular ion, also peaks of mass numbers $2 M-18$ of varying intensity, possibly due to anhydride formation in the inlet system. In general, the facile anhydride formation of the $\mathrm{B}-\mathrm{OH}$ derivatives caused trouble in their purification and made determination of melting points very difficult. Recrystallization from alcohols must be avoided, since esterification easily occurs. This can advantageously be used in some cases to prepare an ethoxy derivative in order to obtain satisfactory elemental analyses.

Qualitative experiments showed that the stability of the $C$-methyl derivatives towards alkaline and acid hydrolysis is approximately the same as that of the borazarothienopyridines studied earlier. ${ }^{2}$ Thus 60 and $75 \%$ of IIIa and IIIb, respectively, was recovered after refluxing for $2 \mathrm{~h}$ with $2 \mathrm{~N}$ aqueous sodium hydroxide. From similar treatment of IVa and IVb, 35 and $50 \%$ of the starting material was recovered. Similar experiments with the 4-desmethyl derivatives corresponding to IVa and IVb only yielded the azines of 3 -formylthiophene. ${ }^{2}$ Refluxing the compounds IIIa, IIIb, IVa, and IVb with concentrated hydrochloric acid for $2 \mathrm{~h}$ led to a recovery of $75-80 \%$ of starting material. The $\mathrm{B}-\mathrm{CH}_{3}$ derivatives IIIc and IVc showed approximately the same stability towards acid hydrolysis. After $2 \mathrm{~h}$ reflux, 75 and $80 \%$, respectively, of the starting material was recovered, including smaller amounts $(5-10 \%)$ of the corresponding $\mathrm{B}-\mathrm{OH}$ derivatives. However, upon alkaline hydrolysis of IIIc and IVc ( $2 \mathrm{~h}$ in refluxing $2 \mathrm{~N}$ sodium hydroxide), complete cleavage of

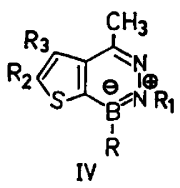

a $\mathrm{R}=\mathrm{OH}, \mathrm{R}_{1}=\mathrm{R}_{2}=\mathrm{R}_{3}=\mathrm{H}$

b R $=\mathrm{OH}, \mathrm{R}_{1}=\mathrm{CH}_{3}, \mathrm{R}_{2}=\mathrm{R}_{3}=\mathrm{H}$

c $\mathrm{R}=\mathrm{CH}_{3} \mathrm{R}_{1}=\mathrm{R}_{2}=\mathrm{R}_{3}=\mathrm{H}$

d R $=\mathrm{R}_{1}=\mathrm{CH}_{3}, \mathrm{R}_{2}=\mathrm{R}_{3}=\mathrm{H}$

e $\mathrm{R}=\mathrm{OH}, \mathrm{R}_{1}=\mathrm{H}, \mathrm{R}_{2}=\mathrm{R}_{3}=\mathrm{Br}$

f $\mathrm{R}=\mathrm{OH}, \mathrm{R}_{1}=\mathrm{CH}_{3}, \mathrm{R}_{2}=\mathrm{R}_{3}=\mathrm{Br}$

g $R=O H, R_{1}=R_{3}=H, R_{2}=N_{2}$

$h \mathrm{R}=\mathrm{OH}, \mathrm{R}_{1}=\mathrm{R}_{2}=\mathrm{H}, \mathrm{R}_{3}=\mathrm{NO}_{2}$

i $R=O H, R_{1}=\mathrm{CH}_{3}, R_{2}=\mathrm{NO}_{2}, \mathrm{R}_{3}=\mathrm{H}$

j $\mathrm{R}=\mathrm{OH}, \mathrm{R}_{1}=\mathrm{CH}_{3}, \mathrm{R}_{2}=\mathrm{H}, \mathrm{R}_{3}=\mathrm{NO}_{2}$

the B-methyl bond occurred and IIIa and IVa were isolated in $65 \%$ and $45 \%$ yields, respectively. These experiments were performed under the same conditions as described in Ref. 2.

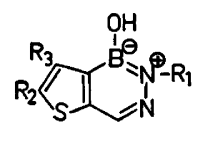

$\checkmark$

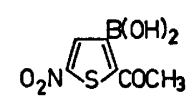

VI

a $\mathrm{R}_{1}=\mathrm{CH}_{3}, \mathrm{R}_{2}=\mathrm{R}_{3}=\mathrm{H}$

b $\mathrm{R}_{1}=\mathrm{CH}_{3}, \mathrm{R}_{2}=\mathrm{H}, \mathrm{R}_{3}=\mathrm{Br}$

c $\mathrm{R}_{1}=\mathrm{CH}_{3}, \mathrm{R}_{2}=\mathrm{R}_{3}=\mathrm{Br}$

d $R_{1}=R_{2}=R_{3}=H$

Brominations. Six different methods of bromination were investigated. These employed bromine in acetic acid, bromine in hydrobromic acid, bromine in thionyl chloride, ${ }^{18}$ bromine in carbon tetrachloride-pyridine, bromine in silver sulfate/sulfuric acid, ${ }^{11}$ and dibromoisocyanuric acid (DBI) in concentrated sulfuric acid.12 13 Only the two last methods were successful. Earlier experiments showed that the desmethyl derivatives of III and IV could be brominated by bromine in silver sulfate/concentrated sulfuric acid, yielding mixtures of 3-bromo and 2,3-dibromo derivatives. ${ }^{14} \mathrm{We}$ studied the bromination of 4-hydroxy-5-methyl-4,5borazarothieno[2,3-c]pyridine (Va) with this reagent. Using one equivalent of bromine gave the 3 -bromo derivative $(\mathrm{Vb})$ in $16 \%$ yield and the 2,3-dibromo derivative (Vc) in $31 \%$ yield. Separation was achieved by precipitation at different $\mathrm{pH}$ values.

Acta Chem. Scand. B 29 (1975) No. 10 
The structures of $\mathrm{Vb}$ and $\mathrm{Vc}$ followed from oxidation with permanganate, which gave 4-bromo-2-thiophenecarboxylic acid ${ }^{15}$ and 4,5dibromo-2-thiophenecarboxylic acid, ${ }^{18}$ respectively. However, attempts to monobrominate IIIa, IIIb, IVa, and IVb with this reagent or with DBI were unsuccessful. Only the dibrominated derivatives were obtained besides starting material. Traces of the monosubstituted derivatives were perhaps present. When two equivalents of bromine or DBI in concentrated sulfuric acid were used, the dibromo derivatives IIId, IIIe, IVe, and IVf were obtained in preparatively useful yields of 63 to $75 \%$. The behaviour of IIIa, IIIb, IVa, and IVb is thus different from that of the parent thieno[2,3-c]pyridine and thieno[3,2-c]pyridine, which with one equivalent of these brominating agents gives the 3-bromo derivatives in about $50-60 \%$ yield. ${ }^{11}$ With the latter compound, $10 \%$ of 2,3-dibromothieno[3,2-c]pyridine was also obtained. ${ }^{17}$ The high tendency for dibromination seems to be partly due to the substituents in the borazaropyridine ring part. It is clear that the introduction of the 4- and 7-methyl groups increases the tendency towards disubstitution. As mentioned earlier, it has been found that compounds with free $\mathrm{C}-\mathrm{H}$ position in the borazaropyridine ring such as Va are brominated in this position by bromine in acetic acid $^{3}$ or by bromine in pyridine-carbon tetrachloride. ${ }^{5}$ It was therefore of interest to find out what happens if this position is blocked by methyl groups. However, no substitution of the thiophene ring was observed under these conditions. We also tried to detect addition products by spectroscopic methods, as it is possible that the substitution of, for instance, $\mathrm{V}$ in the 7-position proceeds via an addition-substitution-elimination mechanism. However, no addition products could be detected.

Attempts to use bromine in thionyl chloride ${ }^{18}$ or hydrobromic acid were carried out, as these reagents selectively and in high yield brominated thieno[2,3-b]pyridine and thieno[2,3-b]pyridine in the 3-position at $100^{\circ} \mathrm{C} .{ }^{17}$ However, with the borazarothienopyridines only recovered starting material and tarry products were obtained under different conditions.

Nitrations. The systems IIIa, IIIb, IVa, and $\mathrm{IVb}$ were nitrated with fuming nitric acid in concentrated sulfuric acid to study the influence of the $C$-methyl group on isomer distribution. For comparison, the nitration of I and II was also investigated to obtain additional information about the effect of ring closure upon isomer distribution.

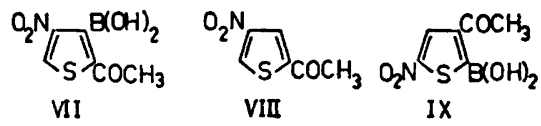

When the mixture from the nitration of I was poured onto ice, 2-acetyl-5-nitro-3-thiopheneboronic acid (VI) precipitated out in $23 \%$ yield. From the mother liquor, by extraction with ether, $19 \%$ of 2-acetyl-4-nitro-3-thiopheneboronic acid (VII) was obtained.

Extraction of the boronic acids with sodium carbonate had to be avoided, as complete de. boronation of VII to 2-acetyl-4-nitrothiophene (VIII) occurred. In a first experiment carried out in this way, a $28 \%$ yield of VI and $29 \%$ of VIII was obtained. Pure VII could also be deboronated to the known VIII ${ }^{10}$ (with the characteristic $J_{24}=1.50 \mathrm{~Hz}$ ) by reflux in acetic acid, which proved the structure of VII. In the same way, VI was deboronated to the known 2-acetyl-5-nitrothiophene ${ }^{10} \quad\left(J_{34}=4.0\right.$ $\mathrm{Hz}$ ).

Upon nitration and acidic work-up, II gave only 3-acetyl-5-nitro-2-thiopheneboronic acid (IX) in $74 \%$ yield. Extraction into sodium carbonate led to immediate deboronation to 4-acetyl-2-nitrothiophene $(\mathrm{X})$ in $70 \%$ yield $\left(J_{35}=1.85 \mathrm{~Hz}\right)$, which of course proves the structure of IX. Again IX could also be deboronated to $X$ by refluxing in acetic acid.

Previously, it was found that in the nitration of 2-formyl-3-thiopheneboronic acid, 2-formyl5-nitro-3-thiopheneboronic acid (22\%) and 4-nitro-2-formylthiophene (57 \%) were formed." It was believed that the latter compound was formed by acid-catalyzed deboronation of 2-formyl-4-nitro-3-thiopheneboronic acid, and the possibility that the facile deboronation was due to neighbouring participation of the nitro group was suggested. As the boronic acids in this case were extracted into sodium carbonate solution, it is obvious from the present results that the very facile alkaline deboronation was overlooked. Such neighbouring group participation is in any case Acta Chem. Scand. B 29 (1975) No. 10 
excluded for IX. It is very probable that we here have an example of the SEl mechanism suggested by Kuivila et al. ${ }^{20}$

$$
\begin{aligned}
& \mathrm{ArB}(\mathrm{OH})_{2}+\mathrm{OH}^{\ominus} \rightleftharpoons \mathrm{ArB}(\mathrm{OH})_{3}{ }^{\ominus} \\
& \mathrm{ArB}(\mathrm{OH})_{3}{ }^{\ominus} \longrightarrow \mathrm{Ar}{ }^{\ominus}+\mathrm{B}(\mathrm{OH})_{3} \\
& \mathrm{Ar}{ }^{\ominus}+\mathrm{H}_{2} \mathrm{O} \longrightarrow \mathrm{ArH}+\mathrm{OH}^{\ominus}
\end{aligned}
$$

The formation of the aryl anion could be strongly facilitated by the two electron-withdrawing groups. The activating effect is evident from the fact that deboronation of VII and IX is complete after about $10 \mathrm{~min}$ at room temperature in $1 \mathrm{~N}$ sodium carbonate solution, while after treatment of $\mathrm{I}$ for $24 \mathrm{~h}$ at room temperature with $2 \mathrm{~N}$ sodium hydroxide, $65 \%$ of this acid was recovered. After the same treatment of II, $10 \%$ of the acid could still be recovered.

The formation of both VI and VII in the nitration of $I$ is expected. In the nitration of 2-acetylthiophene, Gol'dfarb et al. ${ }^{21}$ found that the 4- and 5-nitro derivatives were formed in the proportions 3:1. The known meta directing effect of the boronic acid group ${ }^{22}$ under these conditions deactivates the 4-position more than the 5-position of I. As the total yield is only $60 \%$, and deboronation and some decomposition occurred, some care has to be exercised in drawing more quantitative conclusions. Somewhat surprisingly, the 4:5 ratio in nitration of 2-formylthiophene ${ }^{21}$ and 2-formyl-3-thiopheneboronic acid "is the same (3:1). Nitration of 3-formylthiophene occurs exclusively in the 5-position, ${ }^{23}$ and an introduction of the boronic acid function in the 2-position apparently does not overcome this selectivity.

Previous investigations have shown that 4hydroxy-4,5-borazarothieno[2,3-c]pyridine (Vd) and its 5-methyl derivative $(\mathrm{Va})$ are nitrated by fuming nitric acid in concentrated sulfuric acid in the thiophene ring, yielding the 3-and 2-nitro derivatives in the relative proportions 8:1 and 4:1, respectively. The corresponding nitration of IIIa gave $71 \%$ of a mononitro fraction, which according to NMR consisted of two components, which could be separated by preparative TLC (benzene as eluent) and which were isolated in the proportions 10:1. The major mononitro derivative showed signals at $\delta 10.57,9.07,6.98$, and 2.45 in its NMR

Acta Chem. Scand. B 29 (1975) No. 10 spectrum, while the minor component had peaks at $\delta 10.53,8.53,7.11$, and 2.41. In both cases the relative intensities were $1: 1: 1: 3$. The signals are in both cases due to NH, thiophene hydrogen, $\mathrm{OH}$ and methyl group, but the NMR spectra do not allow definite structure assignments. Attempts to convert the two nitro derivatives by oxidation with alkaline permanganate to known nitrothiophenecarboxylic acids failed. Mainly tarry products were formed. The structures could, however, be proven by preparing authentic 4-hydroxy-7-methyl-2-nitro-4,5-borazarothieno[2,3-c]pyridine through the reaction of VI with hydrazine. This compound was identical (IR, NMR) with the minor nitro isomer formed in the nitration of IIIa. The major isomer therefore must be 4-hydroxy-7-methyl-3-nitro-4,5-borazarothieno$[2,3-c]$ pyridine (IIIg).

Nitration of IIIb under the same conditions gave a $58 \%$ yield of two mononitro derivatives, which again could be separated by preparative TLC and were obtained in the proportions 6:1. The major nitro derivative had in the NMR signals at $\delta 9.12,3.83$, and 2.95 in $\mathrm{CF}_{3} \mathrm{COOH}$, while the minor derivative absorbed at $\delta 8.70,3.87$, and 3.00 . The relative intensities were in both cases $1: 3: 3$, the peaks being due to the thiophenic hydrogen, the $\mathrm{N}-$ $\mathrm{CH}_{3}$ and the $\mathrm{C}-\mathrm{CH}_{3}$ group, respectively.<smiles>CC(=O)c1csc([N+](=O)[O-])c1</smiles><smiles></smiles>

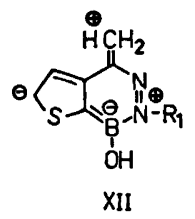

$\begin{array}{ll}\text { a } & \mathrm{R}_{1}=\mathrm{H} \\ \text { b } \mathrm{R}_{1}=\mathrm{CH}\end{array}$

Oxidation attempts were again unsuccessful and the minor component was therefore identified as 5,7-dimethyl-4-hydroxy-2-nitro-4,5-borazarothieno[2,3-c]pyridine (IIIh) by preparing an authentic sample through the reaction of VI with methylhydrazine. The major component therefore must be 5,7-dimethyl-4-hydroxy3-nitro-4,5-borazarothieno[2,3-c]pyridine (IIIi).

Compared with the 7-desmethyl derivatives studied previously, it is evident that the effect of the 7-methyl group on the isomer distribution in nitration is very small. A slight 
increase in the amount of the 3-isomer might have occurred. From both series of compounds, it is also evident that the $5-N-\mathrm{CH}_{3}$ group on the other hand favours 2-substitution over 3 substitution when compared with the $\mathrm{N}-\mathrm{H}$ derivatives.

Namtvedt $t^{4}$ previously studied the nitration of 7-hydroxy-7,6-borazarothieno[3,2-c]pyridine (XIa) and 7-hydroxy-6-methyl-7,6-borazarothieno[3,2-c]pyridine (XIb). In these cases, only the 3-nitro derivatives were obtained.

Nitration of IVa yielded $62 \%$ of a mixture, which according to spectroscopic data and elemental analyses consisted of two mononitro derivatives. Systematic efforts to separate these compounds by column chromatography or TLC failed.

The NMR spectrum in trifluoroacetic acid showed thiophenic signals of equal intensity at $\delta 8.95$ and 8.65 and $C$-methyl signals at $\delta$ 3.07 and 3.04. Apparently the two nitro derivatives were formed in equal amounts. Reaction of IX with hydrazine gave 7-hydroxy-4-methyl2-nitro-7,6-borazarothieno[3,2-c]pyridine (IVg) showing absorptions $\left(\mathrm{CF}_{3} \mathrm{COOH}\right)$ at $\delta$ 8.64 and 3.04 with relative intensities of 3:1. These data, in conjunction with IR and mass spectra, prove that the component with peaks at $\delta$ 8.65 and 3.04 is $I V g$, and the other one is therefore 7-hydroxy-4-methyl-3-nitro-7,6-borazarothieno[3,2-c]pyridine (IVh). Also in the nitration of $\mathrm{IVb}$ two mononitro derivatives which could not be separated were obtained in an 1:1 ratio. The NMR spectrum in $\mathrm{CF}_{3} \mathrm{COOH}$ showed peaks at $\delta 8.89,8.59,3.89,3.85,2.97$, and 2.93. The relative intensities of the pairs of groups were $1: 3: 3$. Synthesis of authentic 4,6-dimethyl-7-hydroxy-2-nitro-7,6-borazaro-

thieno[3,2-c]pyridine (IVi) proved that the peaks at $\delta 8.59,3.85$, and 2.93 belonged to this isomer while the remaining peaks are those of 4,6-dimethyl-7-hydroxy-3-nitro-7,6borazarothieno[3,2-c]pyridine $(\mathrm{IVj})$.

It is thus evident that introduction of a methyl group in the 4-position increases the reactivity of the 2-position over that of the 3-position. This could partly be due to deactivation of the 3-position by steric hindrance from the methyl group (peri effect), but also to an activation of the 2-position by the hyperconjugative effect of the methyl group as illustrated by the resonance structure XII.
Comparing the nitration of the borazarothieno systems with that of the open models, the acetylthiopheneboronic acids, a trend towards increased substitution in the $\beta$-position is noticeable. Thus, while II only yields the $\alpha$ isomer, equal amounts of the $\alpha$ - and $\beta$-isomers are obtained with IV. As discussed earlier by Namtvedt," this provides evidence for the aromaticity of the borazarothienopyridines.

It was previously found that compounds $\mathrm{Va}$ and $\mathrm{Vd}$ are nitrated in the 7-position and $\mathrm{XIa}$ and XIb in the 4-position by nitric acid in acetic anhydride. ${ }^{4}$ It was therefore of interest to find out if these systems could be nitrated in the thiophenic ring part when the 7- and 4-positions are blocked by methyl groups, or if addition products could be detected, which would shed light on the mechanism of this reaction. However, all attempts to nitrate IIIa, IIIb, or IVa, IVb with this reagent led either to recovery of starting material, or if higher temperatures and longer reaction times were used, to increasing tar formation.

\section{EXPERIMENTAL}

4-Hydroxy-7-methyl-4,5-borazarothieno[2,3-c]pyridine $(I I I a)$. To $5.1 \mathrm{~g}(0.030 \mathrm{~mol})$ of 2 acetyl-3-thiopheneboronic acid ${ }^{10}$ dissolved in the minimum amount of ethanol $(95 \%), 1.50 \mathrm{~g}$ $(0.030 \mathrm{~mol})$ of hydrazine hydrate in $10 \mathrm{ml}$ of ethanol was added with stirring. When the exothermic reaction subsided, crystals started to form and the mixture was stirred for $2 \mathrm{~h}$. Evaporation of the ethanol gave $4.8 \mathrm{~g}$ of crude product, which was recrystallized from aqueous ethanol, yielding $4.4 \mathrm{~g}$ ( $88 \%$ ) of the title compound, m.p. $136-143^{\circ} \mathrm{C}$. NMR $\left(\mathrm{CD}_{3} \mathrm{SOCD}_{3}\right)$ : $\delta \quad 10.07$ (NH), 8.40 (OH), 7.90 (H-2), 7.81 (H-3), $2.54\left(\mathrm{CH}_{3}\right) ; J_{23} 4.8 \mathrm{~Hz}$. [Found: C 43.02; $\mathrm{H} 4.29 ; \mathrm{N}$ 17.08. Calc. for $\mathrm{C}_{6} \mathrm{H}_{7} \mathrm{BN}_{2} \mathrm{OS}$ (166.1): C 43.41; $\mathrm{H} 4.25$; $\mathrm{N} 16.88$.]

5,7-Dimethyl-4-hydroxy-4,5-borazarothieno$[2,3-c]$ pyridine (IIIb). From $5.1 \mathrm{~g}(0.030 \mathrm{~mol})$ of 2-acetyl-3-thiopheneboronic acid ${ }^{10}$ in ethanol and $1.4 \mathrm{~g}(0.030 \mathrm{~mol})$ of methylhydrazine, $4.7 \mathrm{~g}$ $(87 \%)$ of the title compound, m.p. $127-135^{\circ} \mathrm{C}$ was obtained in the same way as described above. NMR $\left(\mathrm{CD}_{3} \mathrm{SOCD}_{3}\right): \delta 8.42(\mathrm{OH}), \mathbf{7 . 8 5}$ (H-2), $7.72(\mathrm{H}-3), 3.61\left(\mathrm{NCH}_{3}\right), 2.48\left(\mathrm{CH}_{3}\right) ; J_{23}$ $5.0 \mathrm{~Hz}$. [Found: $\mathrm{C} 46.49 ; \mathrm{H} 4.66 ; \mathrm{N} 15.98$. Calc. for $\mathrm{C}_{7} \mathrm{H}_{9} \mathrm{BN}_{2} \mathrm{OS}$ (180.1): $\mathrm{C} 46.69 ; \mathrm{H} \mathrm{5.03}$; $\mathrm{N}$ 15.56.]

4,7-Dimethyl-4,5-borazarothieno[2,3-c]pyridine (IIIc). In an apparatus connected to $a$ waterseparator, $8.3 \mathrm{~g}(0.050 \mathrm{~mol})$ of IIIa and $150 \mathrm{ml}$ 
of butanol were refluxed for $6 \mathrm{~h}$. Excess butanol was evaporated in vacuo. The residual oil was dissolved in $150 \mathrm{ml}$ of anhydrous ether, cooled to $-10^{\circ} \mathrm{C}$, and $70 \mathrm{ml}$ of $1.0 \mathrm{~N}(0.070 \mathrm{~mol})$ of methylmagnesium iodide added with stirring under nitrogen at such a rate that the temperature did not rise above $0^{\circ} \mathrm{C}$. The mixture was refluxed for $30 \mathrm{~min}$, and after cooling poured into $200 \mathrm{ml}$ of $1 \mathrm{~N}$ hydrochloric acid. The ether phase was separated off and the pH of the water phase adjusted to 7 by addition of sodium bicarbonate, and the water phase was extracted with ether. The combined ether phases were dried over magnesium sulfate and the ether evaporated, yielding $5.9 \mathrm{~g}$ of crystalline product. Recrystallization from $50 \%$ aqueous ethanol gave $5.1 \mathrm{~g}(62 \%)$ of the title compound, m.p. $110-112^{\circ} \mathrm{C}$ after sublimation. $\mathrm{NMR}\left(\mathrm{CD}_{3} \mathrm{SOCD}_{3}\right): \delta 11.15(\mathrm{NH}), 7.86(\mathrm{H}-2)$, 7.62 (H-3), $2.57\left(\mathrm{CCH}_{3}\right), 0.90\left(\mathrm{BCH}_{3}\right) ; J_{23} 5.0 \mathrm{~Hz}$. [Found: C 51.70; H 5.21; N 17.20. Calc. for $\mathrm{C}_{7} \mathrm{H}_{8} \mathrm{BN}_{2} \mathrm{~S}$ (164.1): C 51.25; $\mathrm{H}$ 5.53; $\mathrm{N}$ 17.08.] 7-Hydroxy-4-methyl-7,6-borazarothieno [3,2-c]pyridine $(I V a)$. This compound was prepared in analogy with IIIa from $5.1 \mathrm{~g}(0.030 \mathrm{~mol})$ of 3-acetyl-2-thiopheneboronic acid ${ }^{10}$ and $1.5 \mathrm{~g}$ $(0.030 \mathrm{~mol})$ of hydrazine hydrate. After recrystallization from aqueous ethanol, $4.3 \mathrm{~g}(86 \%)$ of the title compound, m.p. $147-155^{\circ} \mathrm{C}$, was obtained. NMR $\left(\mathrm{CD}_{3} \mathrm{SOCD}_{3}\right): \delta \quad 9.82$ (NH), 8.18 (OH), 8.03 (H-2), 7.55 (H-3), 2.49 (CCH $\left._{3}\right)$; $J_{23} 5.0 \mathrm{~Hz}$. [Found: C 43.42; H 4.24; N 17.13. Calc for $\mathrm{C}_{6} \mathrm{H}_{7} \mathrm{BN}_{2} \mathrm{OS}$ (166.1): $\mathrm{C}$ 43.41; $\mathrm{H} \mathrm{4.25;}$ N 16.88.]

4,6-Dimethyl-7-hydroxy-7,6-borazarothieno$[3,2-c]$ pyridine $(I V b)$. This compound was prepared in analogy with IIIa from $5.1 \mathrm{~g}(0.030 \mathrm{~mol})$ of 3-acetyl-2-thiopheneboronic acid and $1.4 \mathrm{~g}$ $(0.030 \mathrm{~mol})$ of methylhydrazine, with ethanol as solvent. After recrystallization from aqueous ethanol, $4.7 \mathrm{~g}(87 \%)$ of the title compound, m.p. $138-145^{\circ} \mathrm{C}$, was obtained. NMR (CD ${ }_{3}$ $\left.\mathrm{SOCD}_{3}\right): \delta 7.60(\mathrm{OH}), 8.06$ (H-2), $7.56(\mathrm{H}-3)$, $3.61\left(\mathrm{NCH}_{3}\right), 2.53\left(\mathrm{CCH}_{3}\right) ; J_{23} 5.0 \mathrm{~Hz}$. [Found: C 46.40; $\mathrm{H}$ 5.12; $\mathrm{N}$ 15.36. Calc. for $\mathrm{C}_{7} \mathrm{H}_{9} \mathrm{BN}_{2} \mathrm{OS}$ (180.1): C 46.70; H 5.04; N 15.56.]

4,7-Dimethyl-7,6-borazarothieno [3,2-c]pyridine (IVc). This compound was prepared in analogy with IIIc from $8.3 \mathrm{~g}(0.050 \mathrm{~mol})$ of IVa, 150 $\mathrm{ml}$ of butanol, and $70 \mathrm{ml} 1.0 \mathrm{~N}$ of methylmagnesium iodide. After recrystallization from $50 \%$ aqueous ethanol, $4.8 \mathrm{~g}(59 \%)$ of the title compound, m.p. $99-101^{\circ} \mathrm{C}$ after sublimation, was obtained. NMR $\left(\mathrm{CD}_{3} \mathrm{SOCD}_{3}\right): \delta 11.15$ (NH), 8.09 (H.2), 7.61 (H-3), $2.58\left(\mathrm{CCH}_{3}\right)$, $0.87\left(\mathrm{BCH}_{3}\right) ; J_{23} 4.9 \mathrm{~Hz}$. [Found: C 51.72; $\mathrm{H}$ 5.45; $\mathrm{N}$ 17.85. Calc. for $\mathrm{C}_{7} \mathrm{H}_{9} \mathrm{BN}_{2} \mathrm{~S}$ (164.1): C 51.25; $\mathrm{H}$ 5.53; $\mathrm{N} 17.08$.]

4,6,7-Trimethyl-7,6-borazarothieno[3,2-c]pyridine $(I V d)$. This compound was prepared in analogy with IIIc from $9.0 \mathrm{~g}(0.050 \mathrm{~mol})$ of $\mathrm{IVb}, 150 \mathrm{ml}$ of butanol, and $70 \mathrm{ml} 1.0 \mathrm{~N}$ of methylmagnesium iodide. After recrystallization from $50 \%$ aqueous ethanol, $5.9 \mathrm{~g}(66 \%)$ of the title compound, m.p. $48-49^{\circ} \mathrm{C}$ after sublimation, was obtained. NMR $\left(\mathrm{CD}_{3} \mathrm{SOCD}_{3}\right)$ : $\delta 8.04(\mathrm{H}-2), 7.57(\mathrm{H}-3), 3.66\left(\mathrm{NCH}_{3}\right), 2.51$ $\left(\mathrm{CCH}_{3}\right), 0.86\left(\mathrm{BCH}_{3}\right) ; J_{23} 4.9 \mathrm{~Hz}$. [Found: C $53.95 ; \mathrm{H}$ 6.20; $\mathrm{B}$ 6.12; $\mathrm{N}$ 15.68. Calc. for $\mathrm{C}_{8} \mathrm{H}_{11}$ $\mathrm{BN}_{2} \mathrm{~S}$ (178.0): C 53.96; $\mathrm{H}$ 6.23; $\mathrm{B} 6.07 ; \mathrm{N}$ 15.73.]

Bromination with bromine and silver sulfate in conc. sulfuric acid. General procedure. To a solution of $0.0050 \mathrm{~mol}$ of the borazarothienopyridine and $1.55 \mathrm{~g}(0.010 \mathrm{~mol})$ of silver sulfate in $15 \mathrm{ml}$ of conc. sulfuric acid at $0^{\circ} \mathrm{C}, 0.53 \mathrm{ml}$ $(0.010 \mathrm{~mol})$ of bromine was added dropwise. After stirring at $0{ }^{\circ} \mathrm{C}$ for $3-4 \mathrm{~h}$, the reaction mixture was filtered through a glass filter onto $150 \mathrm{~g}$ of ice. The precipitate was washed twice with $5 \mathrm{ml}$ of conc. sulfuric acid, and the filtrate combined with the water phase. The aqueous phase, in which crystals formed, was neutralized with solid sodium bicarbonate and the precipitate filtered off, washed with water and dried. The product was recrystallized from aqueous ethanol, which gave the pure 2,3dibromo derivatives.

2,3-Dibromo-4-hydroxy-5-methyl-4,5-borazarothieno[2,3-c]pyridine (Vc) was obtained from 4-hydroxy-5-methyl-4,5-borazarothieno[2,3-c]pyridine ${ }^{2}$ in $63 \%$ yield, m.p. $161-166^{\circ} \mathrm{C}$. NMR $\left(\mathrm{CD}_{3} \mathrm{SOCD}_{3}\right)$ : $\delta 8.13(\mathrm{H}-7), 7.32(\mathrm{OH})$, $3.60\left(\mathrm{NCH}_{3}\right)$. [Found: C 22.55; H 1.41; $\mathrm{Br}$ 49.18; $\mathrm{N}$ 9.04. Calc. for $\mathrm{C}_{6} \mathrm{H}_{5} \mathrm{BBr}_{2} \mathrm{~N}_{2} \mathrm{OS}$ (323.8): C 22.26; $\mathrm{H}$ 1.56; $\mathrm{Br} 49.36 ; \mathrm{N}$ 8.65.]

2,3-Dibromo-4-hydroxy-7-methyl-4,5-borazarothieno[2,3-c]pyridine (IIId) was obtained from IIIa in $66 \%$ yield, m.p. $182-187^{\circ} \mathrm{C}$. NMR $\left(\mathrm{CD}_{3} \mathrm{SOCD}_{3}\right): \delta 9.83(\mathrm{NH}), 7.80(\mathrm{OH}), \quad 2.33$ $\left(\mathrm{CCH}_{3}\right)$. [Found: C 22.52; $\mathrm{H}$ 1.69; $\mathrm{Br} 49.34$; $\mathrm{N}$ 8.80. Calc. for $\mathrm{C}_{6} \mathrm{H}_{5} \mathrm{BBr}_{2} \mathrm{~N}_{2} \mathrm{OS}$ (323.8): C 22.26; $\mathrm{H}$ 1.56; $\mathrm{Br} 49.39$; $\mathrm{N}$ 8.65.]

2,3-Dibromo-5,7-dimethyl-4-hydroxy-4,5-borazarothieno[2,3-c]pyridine (IIIe) was obtained from IIIb in $69 \%$ yield, m.p. $141-148^{\circ} \mathrm{C}$. NMR $\left(\mathrm{CD}_{3} \mathrm{SOCD}_{3}\right): \delta 7.53(\mathrm{OH}), 3.50\left(\mathrm{NCH}_{3}\right)$, 2.30 $\left(\mathrm{CCH}_{3}\right)$. [Found: C 25.34; $\mathrm{H} 2.01 ; \mathrm{Br} 47.05$; $\mathrm{N}$ 8.51. Calc. for $\mathrm{C}_{7} \mathrm{H}_{7} \mathrm{BBr}_{2} \mathrm{~N}_{2} \mathrm{OS}$ (337.8): C 24.89; H 2.09; $\mathrm{Br} 47.31$; N 8.29.]

2,3-Dibromo-7-hydroxy-4-methyl-7,6-borazarothieno[3,2-c]pyridine (IVe) was obtained from IVa in $75 \%$ yield, m.p. $195-200^{\circ} \mathrm{C}$. NMR $\left(\mathrm{CD}_{3} \mathrm{COCD}_{3}\right): \delta 10.10(\mathrm{NH}), 8.35(\mathrm{OH}), 2.67$ $\left(\mathrm{CCH}_{3}\right)$. As a satisfactory elemental analysis could not be obtained, this compound was transformed to the ethyl ester by refluxing with ethanol; 2,3-dibromo-7-ethoxy-4-methyl-7,6borazarothieno[3,2-c]-pyridine. [Found: C 27.10; $\mathrm{H}$ 3.04; $\mathrm{B} \mathrm{3.04;} \mathrm{Br} 45.72$; $\mathrm{N}$ 7.95. Calc. for $\mathrm{C}_{8} \mathrm{H}_{9} \mathrm{BBr}_{2} \mathrm{~N}_{2} \mathrm{OS}$ (315.8): C 27.32; H 2.58; B 3.07; $\mathrm{Br} 45.43 ; \mathrm{N} 7.96$.]

2,3-Dibromo-4,6-dimethyl-7-hydroxy-7,6-borazarothieno[3,2-c]pyridine (IVf) was obtained from $\mathrm{IVb}$ in $62 \%$ yield, m.p. $171-178^{\circ} \mathrm{C}$. NMR $\left(\mathrm{CD}_{3} \mathrm{SOCD}_{3}\right): \delta 8.41(\mathrm{OH}), 3.43\left(\mathrm{NCH}_{3}\right)$, $2.58\left(\mathrm{CCH}_{3}\right)$. [Found: C 24.84; H 2.39; B 3.20; $\mathrm{Br}$ 47.28; N 8.24. Calc. for $\mathrm{C}_{7} \mathrm{H}_{7} \mathrm{BBr}_{2} \mathrm{~N}_{2} \mathrm{OS}$ (337.8): C 24.89; H 2.09; B 3.20; $\mathrm{Br} 47.31$; N 8.29.]

3-Bromo-4-hydroxy-5-methyl-4,5-borazarothie-

Acta Chem. Scand. B 29 (1975) No. 10 
no[2,3-c]pyridine ( $\mathrm{Vb}$ ). Reacting $0.010 \mathrm{~mol}$ of 4-hydroxy-5-methyl-4,5-borazarothieno[2,3-c]pyridine ${ }^{2}$ with $1.5 \mathrm{~g}$ of silver sulfate in $25 \mathrm{ml}$ of conc. sulfuric acid and $0.53 \mathrm{ml}(0.01 \mathrm{~mol})$ of bromine, according to the general method described above, led upon pouring on water to the precipitation of $1.2 \mathrm{~g}$ of $\mathrm{Vc}$, which was filtered off. The filtrate was then neutralized with solid sodium bicarbonate, and the precipitate $(0.70 \mathrm{~g})$ was filtered off and recrystallized from aqueous ethanol, giving $0.40 \mathrm{~g}(16 \%)$ of the title compound, m.p. $81-88^{\circ} \mathrm{C}$. NMR $\left(\mathrm{CD}_{8} \mathrm{SOCD}_{3}\right): \delta 8.18$ (H-7), $7.85(\mathrm{H}-2), 7.58$ $(\mathrm{OH}), 3.60\left(\mathrm{NCH}_{3}\right)$. [Found: $\mathrm{C} 29.74 ; \mathrm{H}$ 2.53; $\mathrm{Br} 33.62 ; \mathrm{N}$ 11.58. Calc. for $\mathrm{C}_{6} \mathrm{H}_{6} \mathrm{BBrN}_{2} \mathrm{OS}$ (244.9): C 29.42; $\mathrm{H} 2.47 ; \mathrm{Br} 32.63 ; \mathrm{N}$ 11.44.]

Brominations with N,N-dibromoisocyanuric acid in conc. sulfuric acid. General procedure. To a solution of $0.010 \mathrm{~mol}$ of borazarothienopyridine in $25 \mathrm{ml}$ of conc. sulfuric acid at $0^{\circ} \mathrm{C}$, a solution of $2.90 \mathrm{~g}(0.010 \mathrm{~mol})$ of $N, N$-dibromoisocyanuric acid in $20 \mathrm{ml}$ of conc. sulfuric acid was added dropwise with stirring. After 1/2$\mathrm{l} \mathrm{h}$ at $0^{\circ} \mathrm{C}$ the reaction mixture was poured onto $200 \mathrm{~g}$ of ice. The acidic solution was neutralized with solid sodium bicarbonate, the precipitate filtered off, washed with water and dried. After recrystallization from aqueous ethanol, the 2,3-dibromo derivatives were obtained, which had the same physical properties as the samples described above. The following yields were obtained: 2,3-dibromo-4-hydroxy-5-methyl-4,5borazarothieno[2,3-c]pyridine $63 \%$; 2,3-dibromo-4-hydroxy-7-methyl-4,5-borazarothieno[2,3-c]pyridine, $65 \%$; 2,3-dibromo-5,7-dimethyl-4-hydroxy-4,5-borazarothieno[2,3-c]pyridine, $70 \%$; 2,3-dibromo-7-hydroxy-4-methyl-7,6-borazarothieno[3,2-c]pyridine, $62 \%$ and 2,3 -dibromo-4,6-dimethyl-7-hydroxy-7,6-borazarothieno[3,2-c]pyridine, $69 \%$.

Nitration of 2-acetyl-3-thiopheneboronic acid. Work-up $A$. To $20 \mathrm{ml}$ of conc. sulfuric acid and $0.85 \mathrm{ml}$ of fuming nitric acid (d 1.52) cooled to $-20^{\circ} \mathrm{C}, 1.7 \mathrm{~g}(0.010 \mathrm{~mol})$ of 2 -acetyl-3-thiopheneboronic acid ${ }^{10}$ was added with vigorous stirring. After $21 / 2 \mathrm{~h}$ of stirring at $-20^{\circ} \mathrm{C}$, the reaction mixture was poured onto $200 \mathrm{~g}$ of ice. The acidic water phase, which contained a precipitate, was extracted with three $100 \mathrm{ml}$ portions of ether. The combined ether phases were extracted with three $50 \mathrm{ml}$ portions of 1 $\mathbf{N}$ sodium carbonate solution, which immediate. ly were acidified with $5 \mathrm{~N}$ hydrochloric acid. The precipitate was filtered off, washed with water and dried. Recrystallization from aqueous ethanol gave $0.60 \mathrm{~g} \mathrm{(28 \% )} \mathrm{of} \mathrm{2-acetyl-5-nitro-}$ 3-thiopheneboronic acid, m.p. $134-139^{\circ} \mathrm{C}$. NMR $\left(\mathrm{CD}_{3} \mathrm{SOCD}_{3}\right): \quad \delta \quad 8.10(\mathrm{H}-4), 6.1(\mathrm{OH}), 2.12$ $\left(\mathrm{CH}_{3}\right)$. [Found: C 33.85; $\mathrm{H}$ 3.07; N 6.82. Calc. for $\mathrm{C}_{6} \mathrm{H}_{6} \mathrm{BNO}_{5} \mathrm{~S}$ (215.0): C 33.52; $\mathrm{H} \mathrm{2.81;} \mathrm{N}$ 6.52.] The ether phase, which had been extracted with sodium carbonate solution, was washed with water, and dried over magnesium sulfate. Evaporation of the ether gave $0.6 \mathrm{~g}$ of a solid residue, which upon recrystallization from ethanol gave $0.50 \mathrm{~g} \mathrm{(29 \% )} \mathrm{of} \mathrm{2-acetyl-4-ni-}$ trothiophene, m.p. $125-126^{\circ} \mathrm{C}$. NMR (CD $\left.\mathrm{SOCD}_{\mathrm{s}}\right): \delta 9.07$ and 8.47 (thioph.), $2.63\left(\mathrm{CH}_{\mathrm{s}}\right)$; $J_{35} 1.50 \mathrm{~Hz}$. Lit. value, ${ }^{10} \mathrm{~m} . \mathrm{p} .126-127^{\circ} \mathrm{C}$.

Work-up $B$. The experiment was carried out as described above until the mixture was poured onto ice. The crystals $(0.7 \mathrm{~g})$ which formed were filtered off after $15 \mathrm{~min}$, washed with water and dried. Recrystallization from aqueous ethanol yielded $0.50 \mathrm{~g}(23 \%)$ of 2 acetyl-5-nitro-3-thiopheneboronic acid, with the same IR and NMR spectrum as the sample described above. The acidic aqueous phase was extracted three times with $50 \mathrm{ml}$ portions of ether. The combined ether fractions were dried and evaporated. The solid residue $(0.50$ g) was washed with a little chloroform and recrystallized from aqueous ethanol to give $0.40 \mathrm{~g}(19 \%)$ of 2-acetyl-4-nitro-3-thiopheneboronic acid, m.p. $119-124^{\circ} \mathrm{C}$. NMR (CD $\left.\mathrm{SOCD}_{3}\right): \delta 8.99$ (H-5), $6.20(\mathrm{OH}), 2.56\left(\mathrm{CH}_{3}\right)$. [Found: C 33.13; H 3.02; N 6.91. Calc. for $\mathrm{C}_{6} \mathrm{H}_{6} \mathrm{BNO}_{5} \mathrm{~S}$ (215.0): $\mathrm{C}$ 33.52; $\mathrm{H} \mathrm{2.81;} \mathrm{N}$ 6.52.] Deboronation of 2-acetyl-5-nitro-3-thiopheneboronic acid. A solution of $0.43 \mathrm{~g}(0.0020 \mathrm{~mol})$ of 2-acetyl-5-nitro-3-thiopheneboronic acid in $25 \mathrm{ml}$ of acetic acid was refluxed for $3 \mathrm{~h}$ and the solution evaporated to dryness. The solid residue was dissolved in ether. The ether solution was extracted twice with $25 \mathrm{ml}$ portions of sodium carbonate solution and dried over magnesium sulfate. After evaporation of the ether, the residue $(0.25 \mathrm{~g})$ was recrystallized from ethanol, yielding $0.20 \mathrm{~g} \mathrm{(59 \% )}$ of 2-acetyl5-nitrothiophene, m.p. $106-108^{\circ} \mathrm{C}$. NMR $\left(\mathrm{CD}_{3} \mathrm{SOCD}_{3}\right): \delta 8.18$ and 7.97 (thioph.), 2.65 $\left(\mathrm{CH}_{8}\right) ; J_{34} 4.40 \mathrm{~Hz}$. Lit. value, ${ }^{19}$ m.p. $108-$ $109^{\circ} \mathrm{C}$.

Deboronation of 2-acetyl-4-nitro-3-thiopheneboronic acid. A solution of $0.127 \mathrm{~g}(0.0005 \mathrm{~mol})$ of 2-acetyl-4-nitro-3-thiopheneboronic acid in $25 \mathrm{ml}$ of acetic acid was refluxed for $2 \mathrm{~h}$ and worked up as described above. After recrystallization from ethanol, $0.040 \mathrm{~g}(47 \%)$ of 2 acetyl-4-nitrothiophene, m.p. $125-126^{\circ} \mathrm{C}$, was obtained, with the same IR and NMR spectrum as the sample described above.

Nitration of 3-acetyl-2-thiopheneboronic acid. Work-up A. To a solution of $0.85 \mathrm{ml}$ of fuming nitric acid $(d=1.52)$ in $20 \mathrm{ml}$ of conc. sulfuric acid cooled to $0^{\circ} \mathrm{C}, 1.70 \mathrm{~g}(0.010 \mathrm{~mol})$ of 3 acetyl-2-thiopheneboronic acid ${ }^{10}$ was added in portions with vigorous stirring. The reaction mixture was kept for $2 \mathrm{~h}$ at $0^{\circ} \mathrm{C}$ and then poured onto $200 \mathrm{~g}$ of ice. The acidic solution, which contained a precipitate, was extracted three times with $100 \mathrm{ml}$ of ether, and the combi. ned ether phases were then extracted with three $50 \mathrm{ml}$ portions of $1 \mathrm{~N}$ sodium carbonate solution. Acidification of the combined alkaline solutions precipitated $0.6 \mathrm{~g}$ of 4-acetyl-2nitrothiophene. Evaporation of the ether solution gave an additional $0.7 \mathrm{~g}$ (total yield $1.3 \mathrm{~g}, 87 \%$ ) of the title compound, m.p. 62$63^{\circ} \mathrm{C}$ after recrystallization from aqueous 
ethanol. NMR ( $\left.\mathrm{CD}_{3} \mathrm{SOCD}_{3}\right): \delta 8.73$ (thioph.), 8.31, $2.57\left(\mathrm{CH}_{3}\right) ; J_{24} 1.85 \mathrm{~Hz}$. [Found: C 42.5; $\mathrm{H} 3.10 ; \mathrm{N}$ 8.27. Calc. for $\mathrm{C}_{6} \mathrm{H}_{5} \mathrm{NO}_{3} \mathrm{~S}$ (171.0): C 42.10; H 2.95; $\mathrm{N} 8.18$.]

Work-up $B$. The experiment was carried out as described above until the mixture was poured onto ice. The precipitate $(1.8 \mathrm{~g})$ was filtered off and recrystallized from aqueous ethanol, giving $1.6 \mathrm{~g}(74 \%)$ of 3-acetyl-5-nitro-2-thiopheneboronic acid, m.p. $149-154^{\circ} \mathrm{C}$. NMR $\left(\mathrm{CD}_{3} \mathrm{SOCD}_{3}\right): \delta 8.58(\mathrm{H}-4), 6.5(\mathrm{OH}), 2.64\left(\mathrm{CH}_{3}\right)$. [Found: $\mathrm{C} 33.84 ; \mathrm{H}$ 3.05; $\mathrm{N}$ 6.99. Calc. for $\mathrm{C}_{6} \mathrm{H}_{6} \mathrm{BNO} \mathrm{S}_{5} \mathrm{~S}(215.0): \mathrm{C} 33.52 ; \mathrm{H} 2.81 ; \mathrm{N}$ 6.52.]

Deboronation of 3-acetyl-5-nitro-2-thiopheneboronic acid. A solution of $0.43 \mathrm{~g}(0.020 \mathrm{~mol})$ of 3-acetyl-5-nitro-2-thiopheneboronic acid in $25 \mathrm{ml}$ of acetic acid was refluxed for $3 \mathrm{~h}$ and worked up as described above. After recrystallization from ethanol, $0.20 \mathrm{~g}(59 \%)$ of 4-acetyl2-nitrothiophene, m.p. $62-64^{\circ} \mathrm{C}$, and with the same spectroscopic properties as the sample described above, was obtained.

Nitration of 4-hydroxy-7-methyl-4,5-borazarothieno[2,3-c]pyridine. To a solution of $1.66 \mathrm{~g}$ $(0.010 \mathrm{~mol})$ of IIIa in $20 \mathrm{ml}$ of conc. sulfuric acid prepared at $0^{\circ} \mathrm{C}$, a solution of $0.5 \mathrm{ml}$ of fuming nitric acid $(d=1.52)$ in $5 \mathrm{ml}$ of conc. sulfuric acid was added dropwise with stirring. After $2 \mathrm{~h}$ at $0^{\circ} \mathrm{C}$, the reaction mixture was poured onto $200 \mathrm{~g}$ of ice and neutralized with solid sodium bicarbonate. The precipitate was filtered off, washed with water and dried. The crude product $(1.5 \mathrm{~g}, 71 \%)$, consisted of two components according to TLC (silica gel, benzene as eluent). The crude product (100 mg) was eluted five times on a silica gel plate $(2 \mathrm{~mm} \times 20 \mathrm{~cm} \times 20 \mathrm{~cm})$. Between each elution the plate was allowed to dry. Extraction of one of the two bands gave $70 \mathrm{mg}$ of 4-hydroxy-7-methyl-3-nitro-4,5-borazarothieno[2,3c]pyridine, m.p. $155-170^{\circ} \mathrm{C}$. NMR $\left(\mathrm{CD}_{3}\right.$ $\mathrm{SOCD}_{\mathrm{s}}$ ), $\delta 10.57$ (NH), 9.07 (H-2), 6.98 (OH), $2.45\left(\mathrm{CCH}_{3}\right)$. [Found: $\mathrm{C} 34.78 ; \mathrm{H} 3.09 ; \mathrm{N} 19.20$. Calc. for $\mathrm{C}_{6} \mathrm{H}_{6} \mathrm{BN}_{8} \mathrm{O}_{8} \mathrm{~S}$ (211.0): $\mathrm{C} 34.15$; $\mathrm{H} \mathrm{2.87}$; $N$ 19.91.] The other band gave $7 \mathrm{mg}$ of 4 hydroxy-7-methyl-2-nitro-4,5-borazarothieno[2,3c]pyridine, m.p. $175-180^{\circ} \mathrm{C} . \mathrm{NMR}\left(\mathrm{CD}_{3} \mathrm{SOCD}_{3}\right)$ : $\delta 10.53(\mathrm{NH}), 8.53(\mathrm{H}-3), 7.11(\mathrm{OH}), 2.41$ $\left(\mathrm{CCH}_{8}\right)$. [Found: $\mathrm{C}$ 34.68; $\mathrm{H}$ 3.16; $\mathrm{N} 20.08$. Calc. for $\mathrm{C}_{6} \mathrm{H}_{6} \mathrm{BN}_{8} \mathrm{O}_{8} \mathrm{~S}$ (211.0): $\mathrm{C} 34.15 ; \mathrm{H} \mathrm{2.87}$; N 19.91.]

4-Hydroxy-7-methyl-2-nitro-4,5-borazarothieno[2,3-c]pyridine. To a solution of $0.43 \mathrm{~g}(0.0020$ mol) of 2-acetyl-5-nitro-3-thiopheneboronic acid in $20 \mathrm{ml}$ of ethanol, $0.10 \mathrm{~g}(0.0020 \mathrm{~mol})$ of hydrazine hydrate in $20 \mathrm{ml}$ of ethanol was added with stirring. After $4 \mathrm{~h}$, the solution was evaporated to dryness. The residue $(0.35 \mathrm{~g})$ was washed with sodium bicarbonate solu. tion and water. Recrystallization from aqueous ethanol gave $0.20 \mathrm{~g}(45 \%)$ of the title compound, m.p. $175-180^{\circ} \mathrm{C}$, and with the same spectral properties as the sample described above.

Acta Chem. Scand. B 29 (1975) No. 10
Nitration of 5,7-dimethyl-4-hydroxy-4,5-borazarothieno[2,3-c]pyridine. In the same way as described above for the 5-desmethyl derivative, $1.80 \mathrm{~g}(0.010 \mathrm{~mol})$ of IIIb in $20 \mathrm{ml}$ of conc. sulfuric acid was nitrated with $0.5 \mathrm{ml}$ of fuming nitric acid $(d=1.52)$ in $5 \mathrm{ml}$ of conc. sulfuric acid, yielding $1.3 \mathrm{~g}(58 \%)$ of an isomeric mixture. On TLC of $100 \mathrm{mg}, 78 \mathrm{mg}$ of 5,7 . dimethyl-4-hydroxy-3-nitro-4,5-borazarothieno-

[2,3-c] pyridine, m.p. $207-212^{\circ} \mathrm{C}$, was obtained. NMR ( $\left.\mathrm{CF}_{3} \mathrm{COOH}\right): \delta 9.12(\mathrm{H}-2), 3.83\left(\mathrm{NCH}_{3}\right)$, $2.95\left(\mathrm{CCH}_{3}\right)$. [Found: $\mathrm{C} 37.52 ; \mathrm{H} \mathrm{3.62;} \mathrm{N} 18.35$. Calc. for $\mathrm{C}_{7} \mathrm{H}_{8} \mathrm{BN}_{3} \mathrm{O}_{3} \mathrm{~S}$ (225.0): $\mathrm{C} 37.36$; $\mathrm{H}$ 3.58; $\mathrm{N}$ 18.67.] Furthermore, $13 \mathrm{mg}$ of 5,7 -dimethyl4-hydroxy-2-nitro-4,5-borazarothieno[2,3-c]pyridine, m.p. $236-244^{\circ} \mathrm{C}$, was also obtained. $\mathrm{NMR}\left(\mathrm{CF}_{3} \mathrm{COOH}\right): \delta 8.70(\mathrm{H}-3), 3.87\left(\mathrm{NCH}_{3}\right)$, $3.00\left(\mathrm{CCH}_{3}\right)$. [Found: C 37.58; $\mathrm{H} 3.59 ; \mathrm{N} 18.47$. Calc. for $\mathrm{C}_{7} \mathrm{H}_{8} \mathrm{BN}_{8} \mathrm{O}_{3} \mathrm{~S}$ (225.0): C 37.36; $\mathrm{H} \mathrm{3.58}$; N 18.67.]

5,7-Dimethyl-4-hydroxy-2-nitro-4,5-borazarothieno[2,3-c]pyridine. To a solution of $0.43 \mathrm{~g}$ $(0.0020 \mathrm{~mol})$ of 2-acetyl-5-nitro-3-thiopheneboronic acid in $25 \mathrm{ml}$ of ethanol, $0.10 \mathrm{~g}(0.0020$ mol) of methylhydrazine in $20 \mathrm{ml}$ of ethanol was added with stirring. The precipitate $(0.30 \mathrm{~g})$ which formed was filtered off, washed with water and dried. Recrystallization from ethanol gave $0.20 \mathrm{~g}(44 \%)$ of the title compound, m.p. $235-245^{\circ} \mathrm{C}$, with the same spectral properties as the sample described above.

Nitration of 7-hydroxy-4-methyl-7,6-borazarothieno[3,2-c]pyridine. In the same way as described above, $1.66 \mathrm{~g}(0.010 \mathrm{~mol})$ of IVa in $20 \mathrm{ml}$ of conc. sulfuric acid was nitrated with $0.5 \mathrm{ml}$ of fuming nitric acid $(d=1.52)$ in $10 \mathrm{ml}$ of conc. sulfuric acid, yielding $1.3 \mathrm{~g}(62 \%)$ of a yellowish-brown precipitate. The NMR, IR, and mass spectra indicated that the crude product was a mixture of two mononitro derivatives in a 1:1 ratio. In spite of several attempts with thin-layer and column chromatography, no separation was achieved. Also after recrystallization the isomer composition was still 1:1. NMR ( $\left.\mathrm{CF}_{8} \mathrm{COOH}\right): \delta 8.95$ and 8.65 (thioph.), 3.07 and $3.04\left(\mathrm{CCH}_{3}\right)$. [Found: $\mathrm{C} 34.41 ; \mathrm{H}$ 3.06; $\mathrm{N}$ 19.69. Calc. for $\mathrm{C}_{6} \mathrm{H}_{6} \mathrm{BN}_{3} \mathrm{O}_{8} \mathrm{~S}$ (211.0): C 34.15; H 2.87; N 19.91.]

7-Hydroxy-4-methyl-2-nitro-7,6-borazarothieno$[3,2-c]$ pyridine. To a solution of $0.43 \mathrm{~g}(0.0020$ mol) of 3-acetyl-5-nitro-2-thiopheneboronic acid in $20 \mathrm{ml}$ of ethanol, $0.10 \mathrm{~g}(0.0020 \mathrm{~mol})$ of hydrazine hydrate in $20 \mathrm{ml}$ of ethanol was added with stirring. After $4 \mathrm{~h}$ the alcohol was evaporated, yielding a solid residue. Recrystallization from aqueous ethanol gave $0.20 \mathrm{~g} \mathrm{(45 \% )}$ of the title compound, m.p. $190-205^{\circ} \mathrm{C}$. NMR $\left(\mathrm{CF}_{3} \mathrm{COOH}\right): \delta 8.65(\mathrm{H}-3), 3.04\left(\mathrm{CCH}_{3}\right)$. [Found: C 34.63; $\mathrm{H}$ 3.23; $\mathrm{N}$ 19.11. Calc. for $\mathrm{C}_{6} \mathrm{H}_{6} \mathrm{BN}_{8} \mathrm{O}_{3} \mathrm{~S}$ (211.0): C 34.15; H 2.87; N 19.91.]

Nitration of 4,6-dimethyl-7-hydroxy-7,6-borazarothieno[3,2-c]pyridine. In the same way as described above, $1.80 \mathrm{~g}(0.010 \mathrm{~mol})$ of IVb in $20 \mathrm{ml}$ of conc. sulfuric acid was nitrated with $0.5 \mathrm{ml}$ of fuming nitric acid $(d=1.52)$ in 
$10 \mathrm{ml}$ of conc. sulfuric acid, yielding $0.9 \mathrm{~g}$ $(40 \%)$ of a fine yellowish-brown precipitate. The NMR, IR, and mass spectra indicated that this product was a mixture of two mononitro derivatives in the proportions 1:1. In spite of several attempts with TLC and column chromatography, no separation was achieved. Also after recrystallization the isomer composition was still $1: 1$. NMR $\left(\mathrm{CF}_{3} \mathrm{COOH}\right): \delta 8.89$ and 8.59 (thioph.), 3.89 and $3.85\left(\mathrm{NCH}_{3}\right), 2.97$ and $2.93\left(\mathrm{CCH}_{8}\right)$. [Found: $\mathrm{C}$ 37.57; $\mathrm{H}$ 3.93; $\mathrm{N}$ 18.21. Calc. for $\mathrm{C}_{7} \mathrm{H}_{8} \mathrm{BN}_{3} \mathrm{O}_{3} \mathrm{~S}$ (225.0): C 37.36; $\mathrm{H} 3.62 ; \mathrm{N}$ 18.35.]

4,6-Dimethyl-7-hydroxy-2-nitro-7,6-borazarothieno[3,2-c]pyridine. To a solution of $0.43 \mathrm{~g}$ $(0.0020 \mathrm{~mol})$ of 3-acetyl-5-nitro-2-thiopheneboronic acid in $20 \mathrm{ml}$ of ethanol, $0.10 \mathrm{~g}(0.0020$ mol) of methylhydrazine in $10 \mathrm{ml}$ of ethanol was added with stirring. After a few minutes a precipitate formed, which was washed with water and dried. Recrystallization from aqueous ethanol yielded $0.20 \mathrm{~g}(44 \%)$ of the title compound, m.p. $220-230^{\circ} \mathrm{C}$. NMR (CF ${ }^{-}$ $\mathrm{COOH}): \delta 8.59(\mathrm{H}-3), 3.85\left(\mathrm{NCH}_{3}\right), 2.93\left(\mathrm{CCH}_{3}\right)$. [Found: $\mathrm{C}$ 37.92; $\mathrm{H}$ 4.06; $\mathrm{N}$ 17.94. Calc. for $\mathrm{C}_{7} \mathrm{H}_{8} \mathrm{BN}_{3} \mathrm{O}_{3} \mathrm{~S}$ (225.0): C 37.36; $\mathrm{H} \mathrm{3.62;} \mathrm{N} 18.25$.]

NMR spectra were recorded on a Varian A60 NMR spectrometer, mass spectra were obtained with an LKB A-9000 mass spectrometer and IR spectra with a Perkin Elmer 257 grating infrared spectrophotometer. Elemental analyses were carried out by the Analytical Department of the Chemical Center, by Miss Ilse Beetz, Mikroanalytisches Laboratorium, Kronach, Germany and by Dornis und Kolbe, Mikroanalytisches Laboratorium, Mülheim/Ruhr, Germany.

Acknowledgements. Grants from the Swedish Natural Science Research Council to S.G. and from the Royal Physiographic Society in Lund to C.R. are gratefully ackowledged.

\section{REFERENCES}

1. Gronowitz, S. and Bugge, A. Acta Chem. Scand. 19 (1965) 1271.

2. Gronowitz, S. and Namtvedt, J. Acta Chem. Scand. 21 (1967) 2151.

3. Gronowitz, S. and Namtvedt, J. Tetrahedron Lett. (1966) 2967.

4. Namtvedt, J. Acta Chem. Scand. 22 (1968) 1611.

5. Gronowitz, S. and Maltesson, A Acta Chem. Scand. $B$ 27 (1975) 461 .

6. Gronowitz, S. and Michael, U. Ark. Kemi 32 (1970) 283.

7. Florentin, D. and Roques, B. C. R. Acad. Sci. Ser. C 270 (1970) 1608.

8. Roques, B., Florentin, D. and Juhasz, J.-P. C. R. Acad. Sci Ser. C 270 (1970) 1898.
9. Semard, D., Paulmier, C., Morel, P. and Pastour, P. J. Heterocycl. Chem. 9 (1972) 335.

10. Gronowitz, S., Dahlgren, T., Namtvedt, J., Roos, C., Rosén, G., Sjöberg, B. and Forsgren, U. Acta Pharm. Suecica 8 (1971) 623.

11. Derbyshire, D. H. and Waters, W. A. J. Chem. Soc. (1950) 573.

12. Gottardi, W. Monatsh. Chem. 99 (1968) 815.

13. Gottardi, W. Monatsh. Chem. 100 (1969) 42.

14. Gronowitz, S. and Namtvedt, J. Unpub. lished results.

15. Gronowitz, S. Ark. Kemi 8 (1955) 87.

16. Steinkopf, W., Jakob, H. and Penz, H. Justus Liebigs Ann. Chem. 512 (1934) 136.

17. Gronowitz, S. and Sandberg, E. Ark. Kemi 32 (1970) 249.

18. García, E. V., Greco, C. V. and Hunsberger, I. M. J. Amer. Chem. Soc. 82 (1960) 4430 .

19. Rinkes, I. J. Rec. Trav. Chim. Pays-Bas 52 (1933) 538.

20. Kuivila, H. G., Reuwer, J. F. and Mangravite J. A. Can. J. Chem. 41 (1963) 3081.

21. Gol'dfarb, Ya.L., Novikova, E. I. and Belenkii, L. I. Bull. Acad. Sci. USSR, Div. Chem. Sci. (1972) 1142.

22. Harvey, D. R. and Norman, R. O. C. J. Chem. Soc. (1962) 3822.

23. Gronowitz, S., Håkansson, R., Moses, $\mathbf{P}$. and Hörnfeldt, A.-B. Ark. Kemi. 17 (1961) 165.

Received March 26, 1975. 